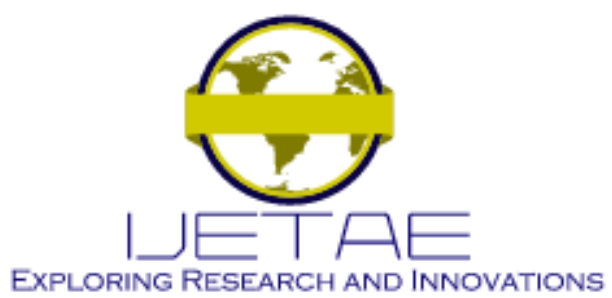

International Journal of Emerging Technology and Advanced Engineering

Website: www.ijetae.com (E-ISSN 2250-2459, Scopus Indexed, ISO 9001:2008 Certified Journal, Volume 11, Issue 09, September 2021)

Manuscript Received: 06 August 2021, Received in Revised form: 08 September 2021, Accepted: 13 September 2021

DOI: 10.46338/ijetae0921_04

\title{
LiDAR/ToF Sensor System Based Various Applications: A Review
}

\author{
Giao N. Pham ${ }^{1}$, Binh A. Nguyen ${ }^{2}$ \\ ${ }^{I}$ Dept. of Computing Fundamentals, FPT University, Hanoi, Vietnam \\ ${ }^{2}$ ICT Department, FPT University, Hanoi, Vietnam
}

\begin{abstract}
The review article will first introduce the basic concept of LiDAR/ToF (Light detection and ranging based on time of flight) sensor system. Then, numerous applications based on LiDAR/ToF sensor are given in specific fields such as consumer electronics, industrial, smart-city, autonomous vehicles, and space \& military. In addition, the technology trends and road map of those products are also discussed in detail. This review will be great references for sales, marketing, and researchers whom plan to work on LiDAR technology.
\end{abstract}

Keywords - Self-driving car, Light distance and ranging, Time of flight, 3D camera.

\section{INTRODUCTION}

The idea of sensing the atmosphere using the light in 1960s is the first application of LiDAR (light detection and ranging), which used ToF (time of light) for distance measurement. And with the development of modern technologies of light, laser, and semiconductor, LiDAR sensor slowly is spreading across application [1]. Nowadays, the researches of self-driving car have involved many researchers in many types of sensors such as RADAR, Ultra-sound, Cameras, LiDAR... among them, LiDAR is a promising technique since the cost for LiDAR sensor is day by day reduce and suitable for massproduction as well as the long-distance detection capacity in comparison with others. Moreover, in other types of application such as consumer electronics [2], smart-city [3], and industrial [4], LiDAR is also showing the better performance and suitable cost. As the consequence, the LiDAR based products are day-by-day increasing.

In this review article, we are going to introduce first the concept of LiDAR sensor system [5]. In addition, the main hardware functions are given to explain why the price of LiDAR sensor system is reducing. Finally, the product and technology trends are also discussed to help readers to understand deeply and have good references in deployment and research. The organization of this review article is as follows.
In the section 2, we are going to discuss the basic concept of LiDAR/ToF sensor system and its main hardware modules. Section 3 will be the main contribution of this review article, which includes the applications of LiDAR/ToF sensor in as consumer electronics, industrial \& smart-city, autonomous vehicles.

\section{LIDAR/TOF SENSOR BASIC CONCEPT}

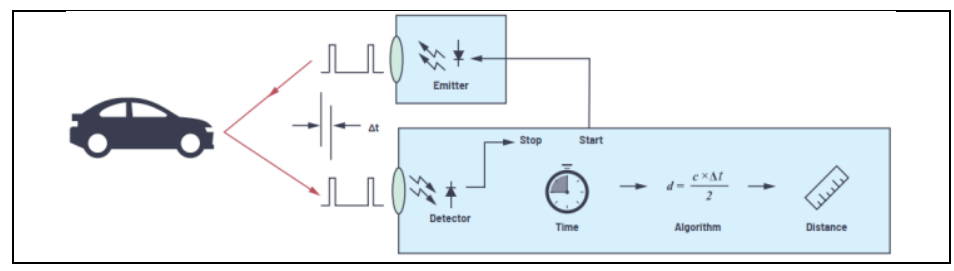

FIGURE I. BASIC CONCEPT OF A LIDAR/TOF SENSOR SYSTEM

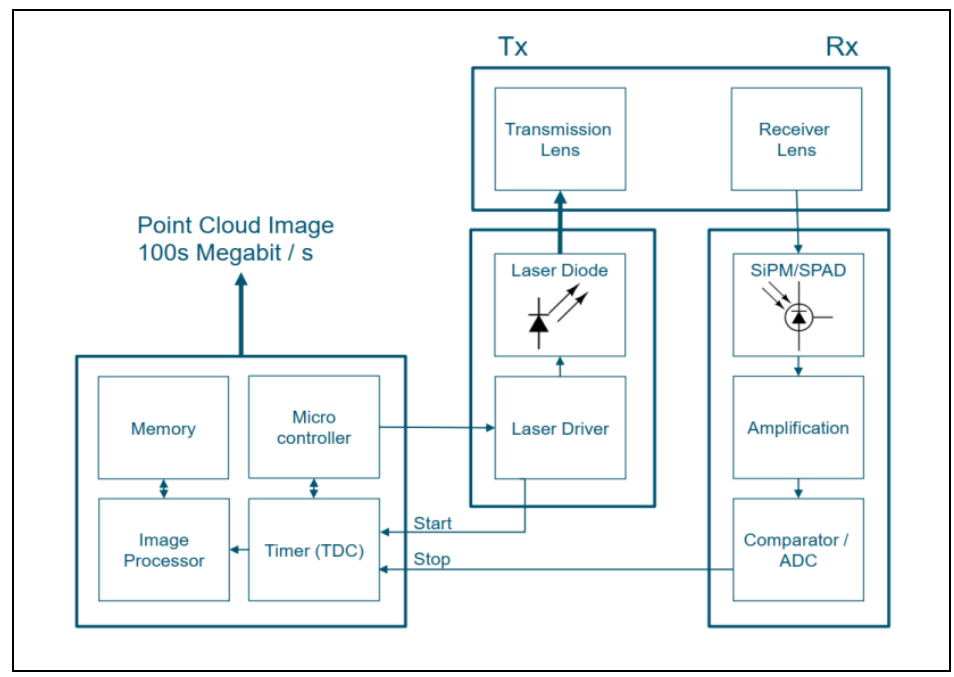

FIGURE II. MAIN HARDWARE FUNCTIONS OF A LIDAR/TOF SENSOR SYSTEM

LiDAR stands for light detection and ranging, which uses ToF (time of flight) to measure the distance of system of destination object via the medium is light. 


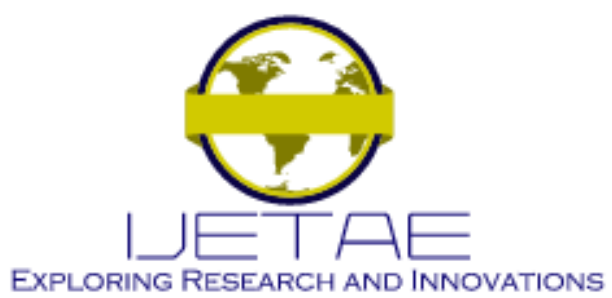

International Journal of Emerging Technology and Advanced Engineering

Website: www.ijetae.com (E-ISSN 2250-2459, Scopus Indexed, ISO 9001:2008 Certified Journal, Volume 11, Issue 09, September 2021)

The Figure I give the steps of algorithm and formulation of distance calculation. Basically, the LiDAR sensor system includes an emitter to send the light, a detector to detect the reflection light. Hence, the detail for a system on chip of LiDAR sensor will includes some important hardware blocks as given in Figure II.

\section{LIDAR/TOF SENSOR BASED APPLICATIONS}

Nowadays, LiDAR sensor systems can be applied into many kinds of application. As can be seen in Figure III, the LiDAR sensor can be applied in but not limited to consumer electronics, automotive, industrial \& smart-city, topography, space \& military.
The various types of application are due to the range of detection in which the LiDAR sensor can be configured to be adapted.

\section{A. LiDAR based application in consumer electronic}

In Figure IV, the trending of 3D camera products is given. Before ToF, 3D cameras use the structured light (ST) technology. The indirect-ToF (iToF) and direct-ToF (dToF) are gradually replaced ST technology with more efficiency in images, videos, and new promising applications. Currently, latest dToF technology in Iphone-12 and IPad pro is leading the 3D camera technology in smart phone and the Android phones will follow it quickly.

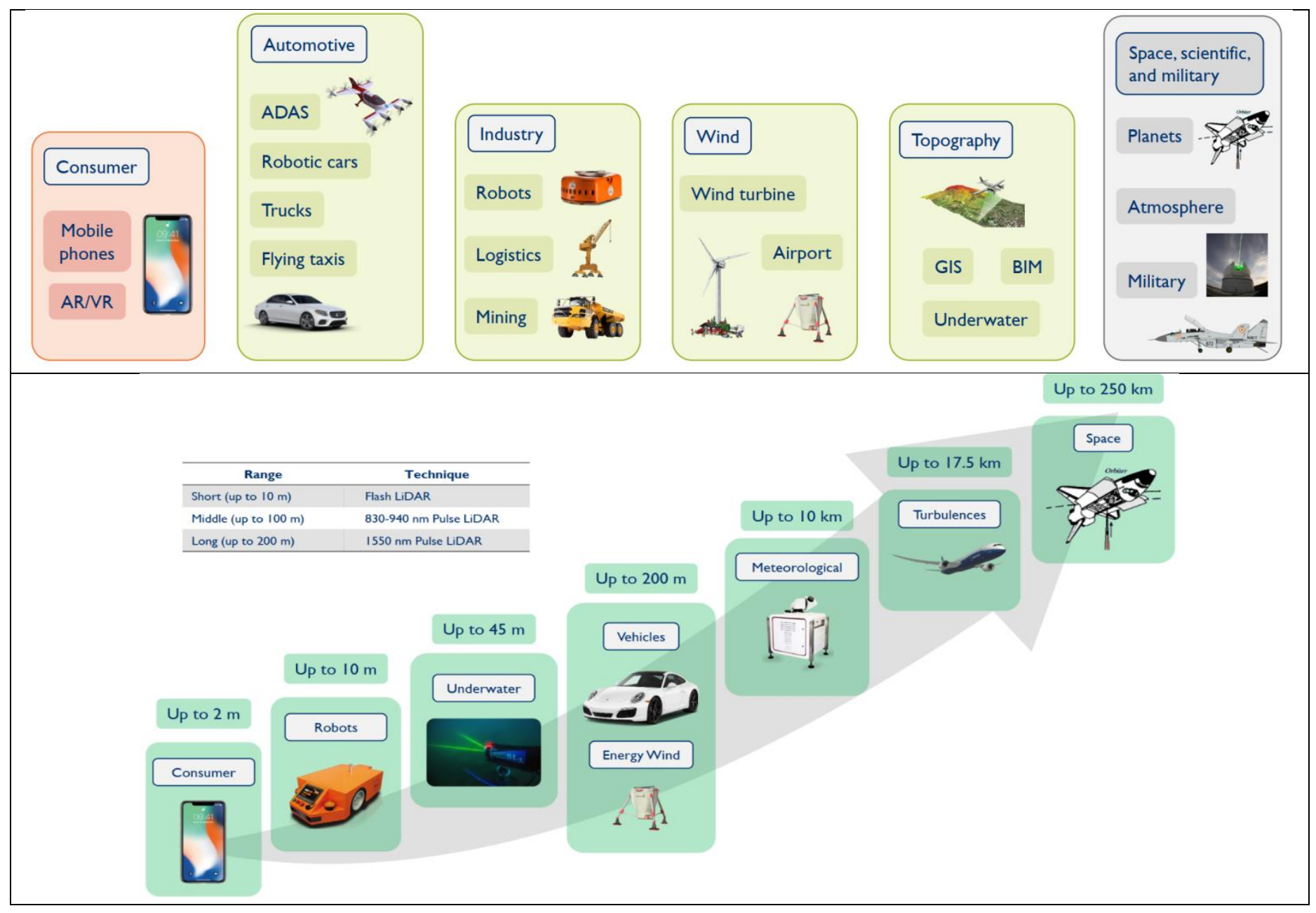

FIGURE III: LIDAR/TOF IN MANY TYPES OF APPLICATION. 


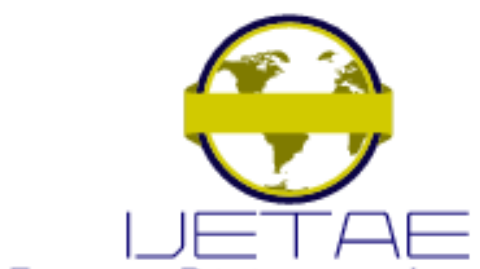

EXPLORING RESEARCH AND INNOVATIONS

International Journal of Emerging Technology and Advanced Engineering

Website: www.ijetae.com (E-ISSN 2250-2459, Scopus Indexed, ISO 9001:2008 Certified Journal, Volume 11, Issue 09, September 2021)

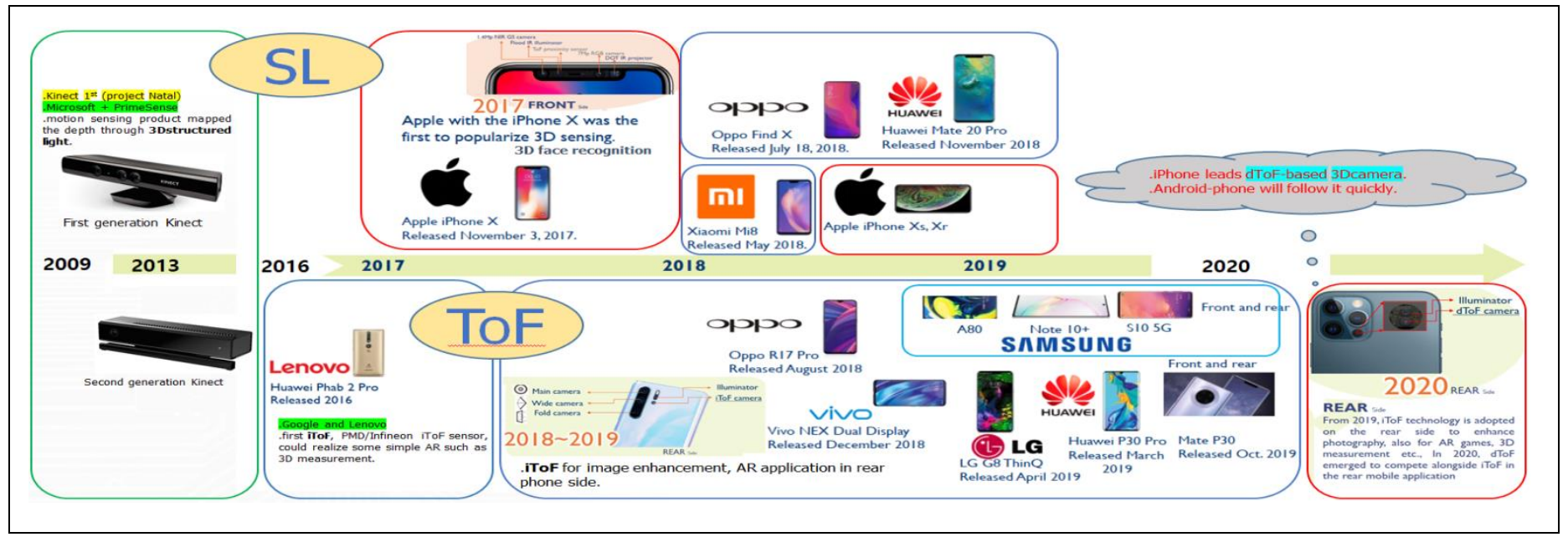

FIGURE IV: LIDAR/TOF SENSOR BASED 3D CAMERA MODULE IN SMART-PHONE.

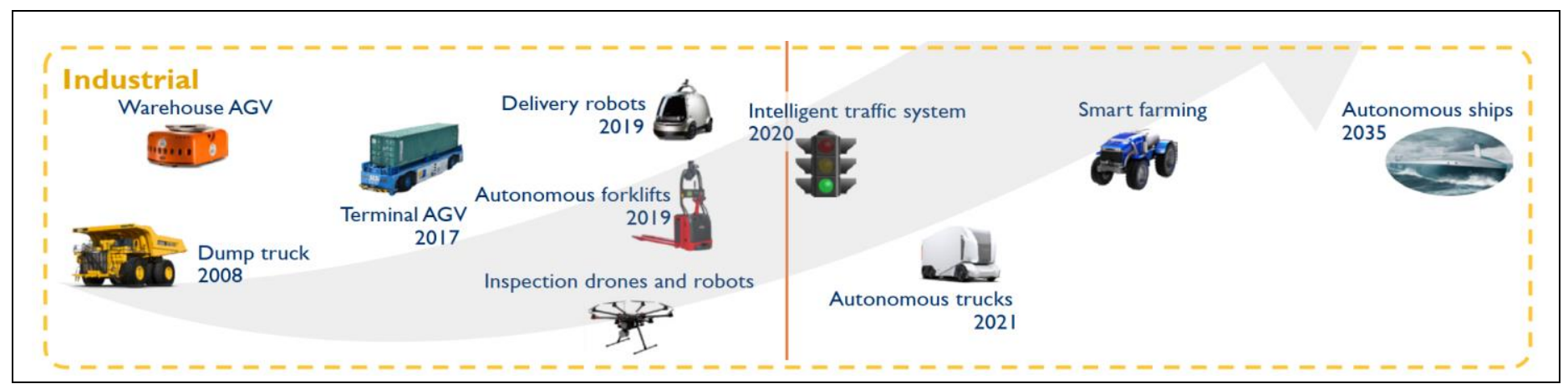

FIGURE V: LIDAR/TOF SENSOR BASED APPLICATIONS IN INDUSTRIAL \& SMART-CITY. 


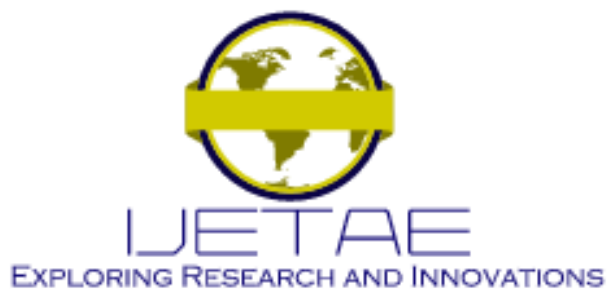

International Journal of Emerging Technology and Advanced Engineering Website: www.ijetae.com (E-ISSN 2250-2459, Scopus Indexed, ISO 9001:2008 Certified Journal, Volume 11, Issue 09, September 2021)

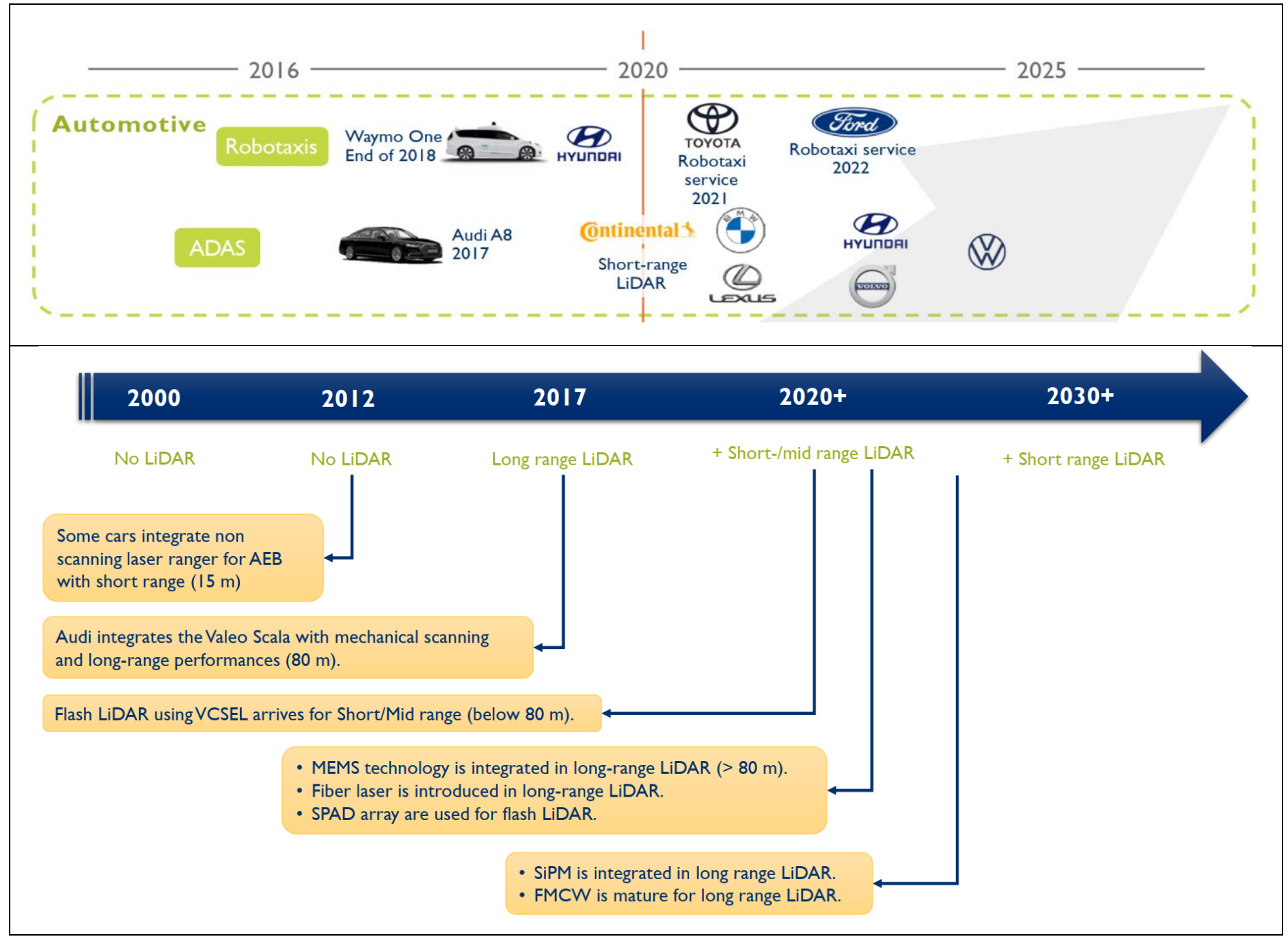

FIGURE VI: LiDAR/ToF sensor based applications in automotive.

\section{B. LiDAR based applications in industrial and smart city}

In industrial \& smart city, there are many applications related to LiDAR as FIGURE V. For smart city application, we consider to the Busan smart city project by iCENT and Qortex DTC, where LiDAR sensor is used to collect and analyse traffic data including walking direction of pedestrian, their traffic volume and number of speeding vehicles. The application of LiDAR in drone with Zenmuse L1, Zenmuse P1 products which let users capture centimeter-accurate data combined with real-time position and orientation compensation technology.
The drone allows photogrammetry professionals the ability to conduct missions requiring 2D orthomosaics, collect oblique images for 3D modeling with centimeterlevel accuracy and acquire ultra-high resolution image data of vertical and slated surfaces from a safe distance. In logistics and building management, factory lines, we can see many possible applications of LiDAR sensor such as people counting, tray-tracking... 


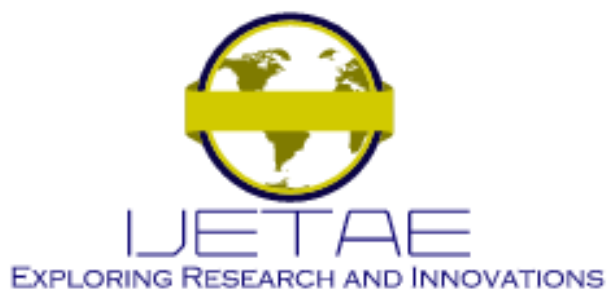

International Journal of Emerging Technology and Advanced Engineering

Website: www.ijetae.com (E-ISSN 2250-2459, Scopus Indexed, ISO 9001:2008 Certified Journal, Volume 11, Issue 09, September 2021)

\section{LiDAR based applications in autonomous vehicles}

The self-driving car is a dream of human in this century. So, the ADAS (advanced driver-assistance systems) is defined with 6 levels. And to make self-driving with highlevels, the LiDAR sensor is a key-technology in cooperation with ML/AI/DL for object detections, object reorganization, and the recommendation systems. FIGURE VI shows its history, present, and future trends of selfdriving car. The most important for the self-driving car too be real is the new technology of LiDAR (VCSEL and SPAD/SiPM) and other sensor systems which can be produced by CMOS technology for mass-production.

\section{CONSLUSION}

In this paper, a novel review of LiDAR/ToF sensor based products is given. Various fields of application such as consumer electronics, industrial \& smart-city, autonomous vehicles are considered in product ecosystem, product supply chain, product players, trend of technology.
Author hopes that the review article will be a good LiDAR/ToF sensor's consulting for marketing, R\&D, and provider departments.

\section{Acknowledgement}

This work is supported by FPT University, Hanoi, Vietnam

\section{REFERENCES}

[1] Nguyen, D. M. et. al. A novel construction for quantum stabilizer codes based on binary formalism. IJMPB 34 (8), 2050059

[2] LiDAR for Automotive and Industrial Applications: Market and Technology Report, YOLE development, 2020.

[3] Dajiang Innovations Technology, https://www.dji.com/kr

[4] 3D Imaging and Sensing-Technology and Market Trends: Market and Technology Report, YOLE development, 2021.

[5] VCSELs-Market and Technology Trends: Market and Technology Report, YOLE development, 2021. 